\title{
La regulación emocional, las terapias y rutinas en alumnado acneae en tiempos de covid-19
}

DOI: $10.46932 / \mathrm{sfjdv2n1-068}$

Received in: November 1st, 2020

Accepted in: December 30th, 2020

\author{
Andrea Luaces Galián \\ Graduada Educación Primaria. Especialista en Audición y Lenguaje. \\ Institution: RG Formación \\ Calle Rosalía de Castro, 44, 30107 Murcia \\ Miguel Ángel Toledo Sandoval \\ Graduado Educación Primaria. Especialista en Audición y Lenguaje. \\ Institution: RG Formación \\ Jennifer Vives Tristán \\ Graduada Educación Primaria. Especialista en Audición y Lenguaje. \\ Institution: RG Formación \\ Calle Rosalía de Castro, 44, 30107 Murcia \\ Paloma Belmonte Sánchez \\ Graduada Educación Primaria. Especialista en Audición y Lenguaje. \\ Institution: RG Formación \\ Calle Rosalía de Castro, 44, 30107 Murcia \\ Jose María Rabal Alonso \\ Profesor ISEN Centro Universitario \\ Institution: ISEN \\ Calle Menéndez y Pelayo, 8, 30204 Cartagena, Murcia \\ E-mail: josemaria.rabal@um.es
}

\section{RESUMEN}

En el presente artículo se expone la importancia de la regulación de las emociones, las terapias y las rutinas en niños que presentan necesidades específicas de apoyo educativo a causa de las sesiones virtuales en tiempos del COVID19, pues se manifiesta un cambio actitudinal en el paso de las sesiones terapéuticas presenciales a las telemáticas. Por tanto, se propone una secuencia didáctica enmarcada para lograr una correcta adquisición de los ítems mencionados y que pueden llevar a cabo tanto familias como profesionales educativos y terapéuticos. De esta manera, el objetivo de este artículo es tratar los aspectos que quedan afectados durante la cuarentena en discentes ACNEAE y establecer actividades para trabajarlos, con el fin de promover una estabilidad positiva para el alumnado.

Palabras claves: COVID-19, secuencia didáctica, actividades, ACNEAE, emociones.

\section{MARCO TEÓRICO}

En el año 2020 se ha vivido una pandemia por el virus Covid-19 que ha supuesto un gran desafío global. No obstante, este caso ya se ha dado, pues durante el siglo XXI surgió el Ébola y la Gripe Porcina, aunque no ha sido hasta el Coronavirus cuando se han tomado la medida de establecer cuarentenas.

Esta misma situación ha conllevado numerosos cambios en los ámbitos sociales, familiares, laborales 
y académicos, puesto que la presencialidad se ha visto mermada frente a las acciones telemáticas.

Uno de los sectores fuertemente afectado ha sido el de la educación, ya que los centros escolares y terapéuticos han transformado completamente la forma de actuar, como se puede apreciar en el estudio de Chacón-Lizarazo y Esquivel Núñez (2020). Este pretende investigar el efecto que ha tenido esta situación en las familias y la población infantil, concretamente quienes se encuentran en situación de diversidad, puesto que estos niños dependen mucho de las rutinas diarias en casa y en el aula, y por ello la cuarentena vivida supuso un cambio en estas dinámicas y sus horarios. Asimismo, el no poder mantener el nivel de actividad anterior a la cuarentena por no poder salir de casa ha supuesto una alteración en el sueño y la alimentación, siendo, según Uscategui (2016), clave para que se activen los procesos cognitivos que intervienen en el aprendizaje. Es por este motivo por el cual los profesionales educativos se han adaptado a una forma de intervenir telemática, para poder establecer una rutina que otorgue estabilidad emocional a los alumnos y tratar de regular las alteraciones anteriores.

Además, al no poder mantener la cantidad de relaciones sociales diarias en pleno confinamiento, en los niños han surgido varios cambios de humor y emocionales, pues numerosos estudios determinan que un total de 74,66\% se enfadan más de lo habitual, un 55,54\% lloran más y un 55,83\% se encuentran más tristes (Berasategi, Idoiaga, Dosil, Eiguren, Pikatza y Ozamiz, 2020). Esto repercute en el nivel de estrés y afecta a las funciones ejecutivas, según Uscategui (2016), por lo que los países procuraban difundir recomendaciones para mantener la salud psicológica.

La potencial forma usual de responder para garantizar el bienestar psicológico y emocional es acudir a un terapeuta, con mayor motivo si los niños tienen un diagnóstico que les determinan en una situación de diversidad. En estos casos, las sesiones con los profesionales se han adaptado al trabajo telemático y ha sido un gran reto afrontar las necesidades mediante la modalidad online.

Por tanto, según la investigación de Chacón-Lizarazo y Esquivel Núñez (2020) llevada a cabo sobre una población de 50 pacientes de hasta los 25 años, de los que un 34\% presentan Síndrome de Down, un 24\% TEA (tipo Asperger), un 28\% TDAH, un 8\% discapacidad cognitiva y un 6\% no se puede definir por ser menores de 5 años y no presentar síntomas más clarificadores. Para ello se desarrolló un cuestionario que consta de dos partes y con respuesta en la escala Likert. La primera trata de las primeras semanas de cuarentena, cuando era imposible continuar con la terapia; y la segunda cuando se retomó en su modalidad virtual.

Los resultados obtenidos de las encuestas realizadas en dicho estudio demuestran que el $86 \%$ confirman que la cuarentena les ha afectado negativamente, correspondiendo el porcentaje restante a la respuesta "indeciso". De este modo se investigaron las áreas que han tenido mayor impacto, siendo la principal la emocional y a continuación el sueño. También se ha recogido que dejar de realizar ejercicio físico ha afectado a los niños en las áreas anteriores, siendo unánime.

En cuanto a la segunda parte del cuestionario, correspondiente con el reinicio de las sesiones 
terapéuticas, el $100 \%$ de los padres admiten que han notado mejoría en sus hijos, por lo que se procede a profundizar en qué áreas exactamente. El 98\% de los encuestados determinan que la mejoría se presentó en las emociones y un $72 \%$ especifican que en el comportamiento, aunque nada en el sueño y en la alimentación.

En relación con las relaciones sociales, todos los encuestados afirmaron el efecto negativo que tuvo sobre las áreas mencionadas (comportamiento, emocional, alimentación y sueño) el dejar de ver a sus amigos y sus compañeros. Asimismo, al reanudar las sesiones virtualmente, el 100\% de los padres notó mejoría, puesto que las sesiones se solían realizar de manera grupal, lo que permitió mantener ciertas relaciones sociales. De hecho, la OMS (2020) destacó la importancia de continuar las relaciones sociales por medio de las redes sociales para mejorar el bienestar psicológico de los niños, en cierta medida.

Además, esta mejoría también se debe a la incorporación progresiva de las rutinas para llevar a cabo dichas sesiones.

En base a todos estos resultados, se puede concluir que las rutinas ayudan a mantener el equilibrio psicológico y emocional y orden en la realización de tareas. También se clarifica que las áreas más afectadas han sido las relativas a las emociones, el comportamiento y el sueño; y que la estrategia para afrontarlos es establecer horarios y rutinas, ya que se mejoró notablemente al continuar la intervención en las sesiones telemáticas, fijar unos objetivos y mantener relaciones sociales.

Como se ha podido apreciar, la institución educativa, junto con los profesionales incluidos los logopedas, ha jugado un papel importante en los niños y jóvenes que han manifestado necesidades educativas especiales temporales o permanentes por no haber recibido suficiente apoyo de aprendizaje y terapia. A pesar de ello, durante el tiempo de confinamiento domiciliario, este tipo de intervenciones, habitualmente realizadas de forma presencial, deben esperar y por ello el tratamiento a distancia ha abierto nuevas vías de intervención para diferentes disciplinas. No obstante, son los padres quienes intervendrán y utilizarán los recursos que tienen en casa para desarrollarse mediante actividades diarias deliberadas y promover el aprendizaje en diferentes áreas que sean beneficiosas para sus hijos.

Pero ¿cómo pueden los tutores o padres asegurarse de que el entorno interactivo que logran sea eficaz y logre unos buenos resultados? Esto resultó en programas de capacitación para padres o como programas de intervención familiar, que ahora se han convertido involuntariamente en pautas básicas para guiar los programas de educación familiar. Los profesionales tienen la gran responsabilidad de capacitar a estas familias y desarrollar habilidades que les darán suficiente estímulo.

¿Qué necesitamos para que el plan obtenga beneficios reales? Primero, los cursos que se pueden realizar online o presencialmente deben enfocarse en brindar las estrategias necesarias para resolver la relación con el niño; desde aspectos básicos de manera teórica hasta la terapia del lenguaje más compleja (como un logopeda), así como estrategias para mejorar el lenguaje en el contexto familiar.

Es importante mencionar que esta realidad desaparecerá en un tiempo y luego se volverá a tener los mismos hábitos. Por eso, es necesario no dejar que los padres asuman solos este nuevo rol, deben ser 
capacitados por profesionales, pero deben entender que son ellos quienes movilizan a los niños a aprender y progresar en cualquier circunstancia y en cualquier momento.

Es imperativo fortalecer sus habilidades en base al apoyo a sus roles, pues de esta manera tendrán un impacto positivo en el crecimiento del niño.

Siguiendo la línea anterior, además de intervenir y continuar los padres con el tratamiento pedagógico, también están creando una pequeña rutina que ayuda a mantener estabilidad emocional en sus hijos, lo cual es ampliamente positivo. No obstante, cuando se habla de rutinas en el contexto educativo puede parecer que se desvinculan del aprendizaje basado en intereses, necesidades y en la autonomía del niño. Sin embargo, instalar unas rutinas en los niños puede suponer la aparición de nuevos procesos pedagógicos enriquecedores, como relata Pulido (2013).

Dentro de las rutinas se incluyen tanto hábitos de orden, aseo, alimentación, como de comportamientos. Rimoli y Ros (2009) comentan que en ocasiones las rutinas se perciben como un mecanismo de control social que a través de un entrenamiento el niño adquiere conductas socialmente válidas. Se debe abandonar esta concepción, ampliar este concepto y verlo como una propuesta de aprendizaje.

Tal y como dice Pulido (2013), nos enfrentamos al reto de concebir las rutinas como un aspecto básico en el desarrollo del niño, transformando estas acciones en acciones cotidianas significativas que ayuden al niño en su desarrollo y a mejorar su autoconcepto. Los docentes tienen que valorar todos los momentos y espacios donde se desempeña su trabajo diariamente como una oportunidad de aprendizaje.

Según Zabalza (1996), consolidar las rutinas como escenarios de aprendizaje tiene diversas funciones, entre las que destacan: dotan a niños y profesores de libertad y seguridad de movimiento, como ya saben lo que va a ocurrir a continuación hace que puedan centrar su foco de atención en la actividad que están haciendo en ese momento. Además, los contextos naturales nos ofrecen la oportunidad para introducir nuevos contenidos que surjan de forma espontánea.

Por lo tanto, llevar a cabo rutinas nos ofrece desarrollar la autonomía, fomentar la toma de decisiones en la resolución de problemas con una participación activa por parte del alumnado, teniendo en cuenta las fases de desarrollo en las que se encuentran los niños.

En el momento que intervienen con personas de distintas edades y distinta procedencia en actividades como las entradas y salidas, el momento de la comida o higiene (acciones cotidianas) ayudan al desarrollo de la socialización, autonomía y equilibrio emocional. (De Pol y Llenas, 2007).

Por todo esto se debe entender las rutinas como un elemento pedagógico que va más allá de la repetición mecánica, sobre todo en la etapa de Educación Infantil. Los momentos diarios de interacción entre los adultos y niños o entre iguales son momentos privilegiados en los que el niño socializa, interactúa y respeta creando relaciones sólidas y estables.

No obstante, debido a la situación actual, las restricciones impiden en numerosas ocasiones mantener 
contacto con los compañeros escolares de los niños, por lo que toda interacción se limita entre padres e hijos. Por tanto, son los progenitores quienes tienen que implicarse en la labor educativa, para poder trabajar con sus hijos con el fin de que tengan una mejor calidad educativa, social, emocional, ... en dicha delicada situación.

De esta manera y en línea con la idea anterior, cabe resaltar la importancia de la educación emocional en los niños, ya que se debe trabajar desde edades tempranas para ir desarrollando las emociones, pues es fundamental que los niños identifiquen en qué estado de ánimo se encuentran para que puedan aprender un contenido en la escuela. Es por esto que la educación emocional es determinante para lograr una educación, ya que si el niño no está de buen ánimo es imposible que entienda y aprenda unos contenidos.

Los niños deben aprender a gestionar sus sentimientos, cuando logren la capacidad de reconocer sus propios sentimientos y los de los demás, solamente ahí van a ser felices, estarán motivados y emplearán adecuadamente las relaciones con los demás, también van a saber adecuarse a distintas situaciones que se les presenten.

Para los alumnos con necesidades educativas es verdaderamente importante conocerse emocionalmente, ya que es un paso más en su educación y esto le ayudará en su autoestima y a las relaciones con los demás. Desde el aula podemos trabajar estas emociones, se pueden realizar actividades comparando nuestro cuerpo con alguna emoción, para así explicar a los alumnos la conexión que tiene nuestro cuerpo con las emociones que sentimos. También se pueden realizar actividades de relajación para que el alumno pueda calmarse y liberar el estrés, esta actividad se debe hacer cuando el alumno tiene alguna conducta disruptiva para que aprenda a expresar sus emociones de otra manera, como por ejemplo calmandose y respirando. Otra actividad para trabajar las emociones para un aula especializada como para un aula ordinaria es relacionar estas emociones con colores, de esta forma al alumno con necesidad le será más fácil diferenciarlas y percibirlas. No obstante, a continuación se detalla una propuesta didáctica para tratar las emociones con el alumnado que presenta necesidades educativas.

\section{SECUENCIA DIDÁCTICA}

Por tanto, se plantea una serie de actividades que se compone de una secuencia didáctica en la que se desarrolla un proceso de conocimiento, comprensión, regulación y gestión de emociones, con la finalidad de dar apoyo pedagógico al alumnado con necesidades educativas y trabajar con ellos un tema muy importante y mermado por la situación derivada del COVID-19: las emociones. Además, las siguientes actividades pueden ser desarrolladas en un aula o en casa, pues se detallan las pautas necesarias para su puesta en práctica.

\section{ACTIVIDAD 1}

Nombre de la actividad: comenzando en las emociones

Objetivo: conocer y comprender las principales emociones. 
Desarrollo de la actividad: para comprender las principales emociones es eficaz el uso de recursos, como son los libros. Por ello, en este caso se leerá El monstruo de colores y se llevarán a cabo actividades para trabajar las emociones, pues dicho libro trata de un monstruo que no se aclara con las emociones y tiene que comprenderlas para poder entenderse a sí mismo. Por tanto, esta secuencia didáctica comienza con esta primera actividad, consistente en la lectura de dicho libro. Es importante realizar una lectura comprensiva y reflexiva, así como observar atentamente las ilustraciones.

Durante la lectura, es conveniente hacer preguntas como “¿estás de acuerdo con la situación que pone?”, “¿piensas que ese color representa a esta emoción?”, “¿has sentido esta emoción?”, ¿en qué otros momentos crees que puede manifestarse esta emoción?”. Además, se considera pertinente dar la posibilidad de asociar las emociones con los colores que cada uno considere y así no consolidar estereotipos sociales, por lo que esta es una oportunidad para pensar si los colores aportados por el libro son adecuados o los cambiaría por otros.]

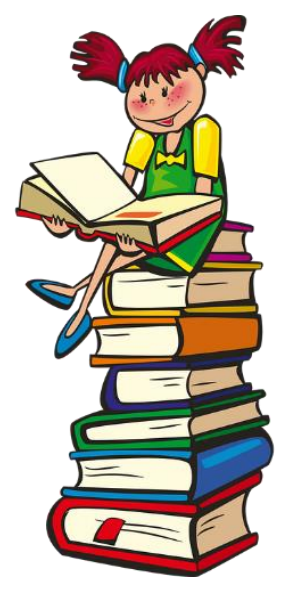

Materiales: el libro El monstruo de colores, que se puede comprar u obtener de la biblioteca.

\section{$\underline{\text { ACTIVIDAD } 2}$}

Nombre de la actividad: asociando colores y emociones

Objetivo: clasificar las emociones a colores para su comprensión.

Desarrollo de la actividad: siguiendo la línea de la actividad anterior surge la presente actividad, como inspiración del libro leído previamente. En este caso se presenta una serie de objetos cotidianos de varios colores, como los del libro (amarillo, azul, rojo, negro y verde) o los que se estime conveniente, además de cinco recipientes. De modo que, primero, se escribirán los nombres de las emociones en papeles, como etiquetas, para situarlos en los recipientes. Después se tienen que clasificar los objetos en los distintos recipientes para comprender las emociones y como primer paso para saber diferenciarlas. 


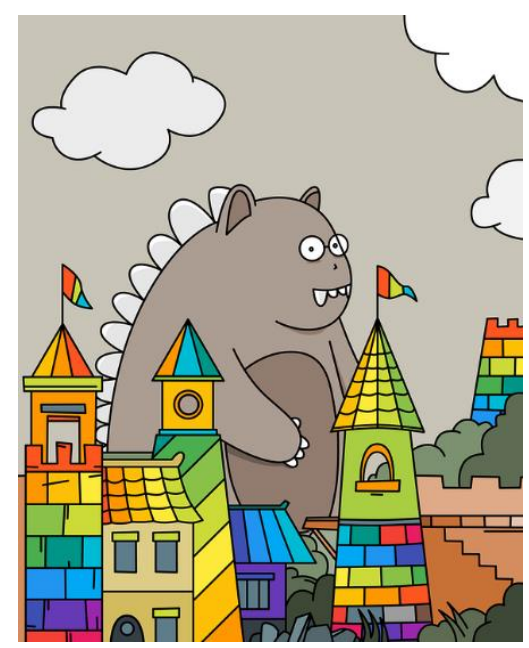

Materiales: los objetos que se dispongan de los distintos colores, pueden ser botones, hilos, lápices, papeles, canicas, etc. También se precisarán recipientes, como botes, cajas o bolsas.

\section{$\underline{\text { ACTIVIDAD } 3}$}

Nombre de la actividad: buscando las diferencias

Objetivo: reconocer las emociones y sus diferencias.

Desarrollo de la actividad: se exponen dos imágenes en las que se encuentran personas expresando emociones diferentes, de modo que el niño tiene que identificarlas y encontrar las diferencias entre las dos fotos.

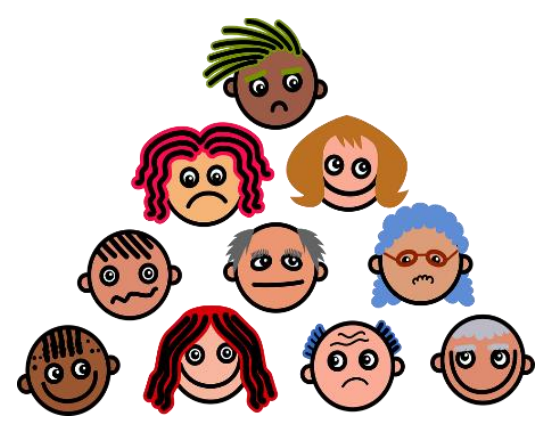

Materiales: imágenes de personas expresando diferentes emociones.

\section{$\underline{\text { ACTIVIDAD } 4}$}

Nombre de la actividad: diario de las emociones

Objetivo: expresar las emociones.

Desarrollo de la actividad: esta actividad se dedica a expresar las emociones con la asociación de los colores anteriores. Por tanto, se disponen de folios y lápices de colores, de forma que se pregunta “¿cómo te sientes hoy?” y “¿qué emoción te representa hoy?”. Entonces se elegirá el color pertinente y se expresará la 
emoción realizando un dibujo.

Esta actividad se puede llevar a cabo a diario y es eficaz para conocer las propias emociones y las situaciones que producen cada emoción, así como introducción a la autogestión y regulación emocional.

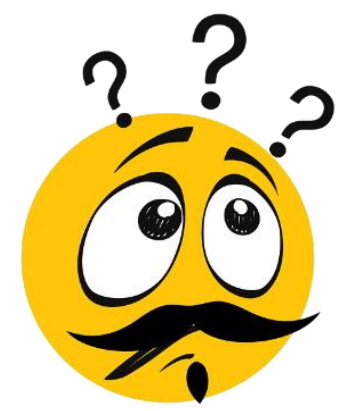

Materiales: folios y lápices de colores.

\section{$\underline{\text { ACTIVIDAD } 5}$}

Nombre de la actividad: el semáforo de las emociones

Objetivo: conocer y regular las emociones cuando se presentan conductas disruptivas y cuando se encuentra en calma.

Desarrollo de la actividad: para esta actividad se presenta un semáforo y se explica la que lo ideal es que se encuentre en verde, pero en ocasiones cambia de color, por lo que hay que saber qué hacer para cambiar el color del semáforo.

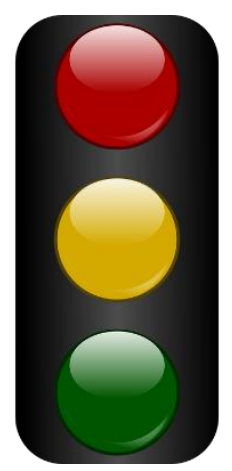

En primer lugar, se procura que el niño asocie las conductas disruptivas y las emociones que se presentan en dichas situaciones con el color rojo. Del mismo modo que las emociones positivas cuando se está en calma se sitúan en el color verde. Por tanto, el color amarillo se destina al paso del estado de calma a dichas conductas.

Así, se le pide al niño que sitúe diferentes tarjetas con emociones, tanto palabras como imágenes, en el color del semáforo apropiado.

Posteriormente se introducen ejercicios de relajación y respiración para que pueda cambiar al estado de calma cuando presente una conducta disruptiva.

Estas pautas se deben practicar reiteradamente para poder dominarlas y garantizar una efectiva 
autorregulación emocional, por lo que el semáforo sirve para saber en qué color se encuentra y así saber los pasos que tiene que llevar a cabo para tranquilizarse.

Materiales: una imagen de un semáforo y tarjetas de emociones.

\section{$\underline{\text { ACTIVIDAD } 6}$}

Nombre de la actividad: catalogando emociones

Objetivo: asociar las emociones con sus expresiones.

Desarrollo de la actividad: se dispone de varios dibujos de monstruos, como los del libro inicial, u otros personajes que sean de interés del niño. Cada uno de ellos expresa una emoción diferente y se tiene que clasificar cada imagen con unas tarjetas donde aparezca el nombre de las emociones.

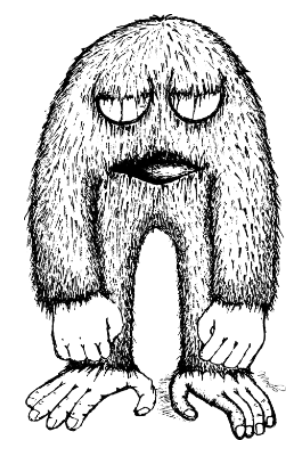

Materiales: tarjetas con las imágenes de los personajes expresando diferentes emociones y otras con los nombres de las emociones en cuestión.

\section{$\underline{\text { ACTIVIDAD } 7}$}

Nombre de la actividad: emociones en tiempos de COVID

Objetivo: saber reconocer las emociones en personas que llevan mascarillas.

Desarrollo de la actividad: en esta actividad se utilizan imágenes de personas, que pueden ser fotografías de los miembros familiares, con y sin mascarilla, de forma que se muestren aquellas en las que llevan puesta la mascarilla y el niño tiene que adivinar la emoción y asociarla a la foto sin mascarilla.

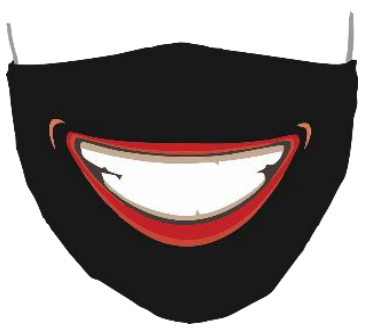

Materiales: fotografías de personas con y sin mascarilla. 


\section{$\underline{\text { ACTIVIDAD } 8}$}

Nombre de la actividad: nos convertimos en mimos

Objetivo: expresar diferentes emociones.

Desarrollo de la actividad: en esta ocasión se dispone de una ruleta en la que se encuentran los nombres de las emociones, de modo que el niño tiene que tirar de la ruleta $y$, estando frente a un espejo, tiene que expresar con la expresión corporal y facial la emoción en cuestión. Para ello tiene que poner en práctica lo aprendido en las actividades anteriores, aunque si no sabe cómo manifestar la emoción pertinente, imitará la representada por el adulto que lo acompañe.

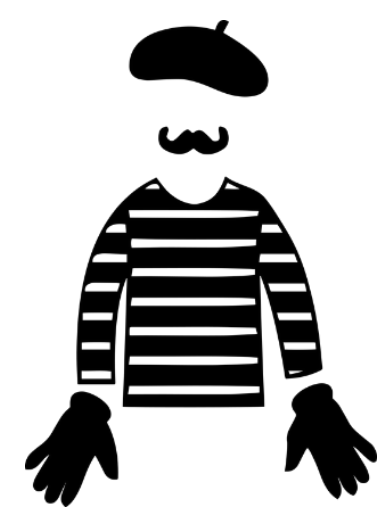

A

simismo, se realizará estas acciones utilizando la mascarilla.

Materiales: ruleta (comprada o de elaboración propia) y tarjetas con el nombre de las emociones.

\section{$\underline{\text { ACTIVIDAD } 9}$}

Nombre de la actividad: teatralizando

Objetivo: practicar la expresión de emociones.

Desarrollo de la actividad: en esta actividad se adopta la metodología de simulación, en la que se llevan a cabo escenografías o role playing. Consiste en presentar diferentes situaciones que se tienen que representar entre niño y adulto o bien entre un grupo de niños, puesto que permite trabajar la socialización. Las situaciones que se plantean son:

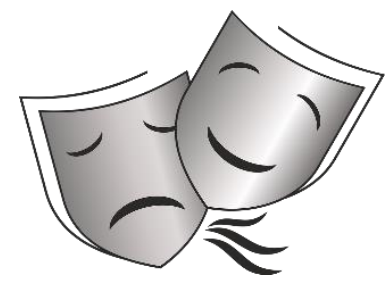

- $\quad$ Ir a la mesa a comer y encontrarse con su plato favorito.

- $\quad$ Ir al colegio.

- Jugar con amigos. 
- $\quad$ No encuentra su juguete favorito.

- $\quad$ Pisar un chicle que estaba en el suelo.

- $\quad$ Alguien le quita algún objeto, como el estuche.

En primer lugar, se tiene que decir la emoción que sentiría si se encontrara en esa situación y el porqué. Tras ello se procede a representar cada acción.

Materiales: se pueden hacer tarjetas escribiendo las situaciones en folios y colocarlos en un recipiente para que el niño las coja aleatoriamente, aunque es opcional, pues no es imprescindible el uso de materiales para realizar esta actividad.

\section{$\underline{\text { ACTIVIDAD } 10}$}

Nombre de la actividad: escritores por un día

Objetivo: estimular la creatividad literaria y fomentar el trabajo emocional.

Desarrollo de la actividad: para desarrollar esta actividad se utilizan las tarjetas con los nombres de las emociones que se han usado en las actividades anteriores, junto a otras tarjetas que cuenta con personajes, como son madre, hermano, hija, vecino, amigo, desconocido; de modo que se coge, de forma aleatoria, una de cada tipo y con las que toque se tiene que escribir una historia. Para ello es conveniente exponer y seguir las fases del proceso de escritura: planificación, redacción, revisión y mejora.

Dependiendo del nivel de competencia lingüística, concretamente la escritora, del niño, la historia ha escribir puede variar desde un microrrelato y cómic hasta un cuento, pues el nivel de complejidad aumenta. Es importante conocer al niño y adecuarse a sus necesidades y características, ya que se establece un punto de partida y progresivamente se aumenta el grado de dificultad.

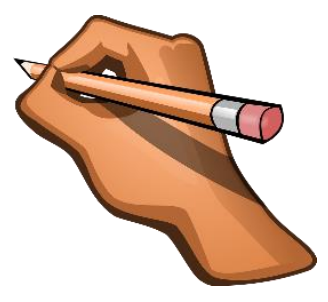

Materiales: folios, lápiz y tarjetas de emociones y personajes.

\section{IMPLICACIONES EDUCATIVAS Y CONCLUSIÓN}

Actualmente, debido al COVID-19 y todo lo que ello conlleva emocionalmente, supone un gran reto para la educación trabajar los aspectos emocionales en niños que presentan necesidades específicas de apoyo educativo. Por ello, con la secuencia de actividades presentada anteriormente se pretende que los niños con 
necesidades específicas consigan regular y conocer tanto sus propias emociones como las de los demás. Para trabajar esto último, esta secuencia incluye actividades para desarrollar el reconocimiento de emociones adaptadas a las necesidades educativas actuales, como son las actividades de reconocimiento con mascarilla o de dramatización.

Por otro lado, con las actividades planteadas se espera despertar la motivación e ilusión de los alumnos para trabajar las emociones, actualmente tan importante para el correcto desarrollo de los niños en todos los aspectos, tanto a nivel madurativo como social y educativo. A su vez, es indispensable para paliar y compensar aquellas carencias afectivas y emocionales debido a la situación derivada del COVID-19.

Por todo ello, en la secuencia didáctica se dan pautas para trabajar algo tan esencial como es el conocimiento, la comprensión, regulación y gestión de emociones. Es esencial la puesta en práctica de estas actividades en las rutinas diarias de los niños que presenten necesidades específicas, tanto dentro del aula como en su propio hogar, para conseguir un correcto desarrollo. 


\section{REFERENCIAS}

Berasategi Sancho, N., Idoiaga Mondragón, N., Dosil Santamaría, M., Eiguren Munitis, A., Pikatza Gorrotxategi, N. y Ozamiz Echevarria, N. (2020). Las voces de los niños y de las niñas en situación de confinamiento por el COVID-19. País Vasco, España: Servicio de Publicaciones de la Universidad del País Vasco.

Chacón-Lizarazo, O. M. y Esquivel Núñez, S. (2020). Efectos de la cuarentena y las sesiones virtuales en tiempos del COVID-19. Eco matemático, 11(1), 18-26.

De Pol, C. y Llenas, P. (2007). Pequeños y competentes: de las actividades cotidianas al aprendizaje de la autonomía. En M. Antón (coord.). Planificar la etapa de 0-6. Compromiso de sus agentes y práctica cotidiana (pp. 69-127). Barcelona: Grao

Ilabaca, M. P. (2020, 11 septiembre). Terapias para niños con necesidades educativas especiales. Centro de Comunicación de las Ciencias. Obtenido de: https://ciencias.uautonoma.cl/noticias/terapias-para-ninoscon-necesidades-educativas-especiales/

Miniland (2018, 17 septiembre). La importancia de la educación emocional infantil en las aulas. Obtenido de: https://spain.minilandeducational.com/school/importancia-educacion-emocional-infantil-aulas

Pulido, J. M. (2013). Las rutinas en educación inicial: entre la mecanización y la transformación. Educación y ciudad, 24, 81-92.

Rimoli, M. y Ros, N. (2009). Rutinas y situaciones didácticas. En D. Horacio Kaplan (coord.). Rutinas y rituales en Educación Inicial. Cómo se organiza la vida cotidiana (pp. 98-108). Buenos Aires: Ediciones Novedades Educativas.

Uscategui, M. Boscan, A. (2016). Neuroeducación Un Enfoque Motivador Para el Proceso de Aprendizaje del Cálculo Inicial En La Universidad Francisco de Paula Santander. Encuentro Internacional en Educación Matemática, 8(1), 16-24.

Zabalza, M. (1996). Didáctica de la educación infantil. Madrid: Narcea 